\title{
Automated colorimetric determination of recombinant fungal laccase activity in fermentation samples using syringaldazine as chromogenic substrate
}

\author{
K. A. Holm, D. M. Nielsen and J. Eriksen \\ Analytical Biotechnology $R$ \& D, Enzyme Research, Novo Nordisk Research \\ Institute, DK-2880 Bagsvaerd, Denmark
}

An automated Cobas Fara method was developed determining the activity of recombinant $M$. thermophila laccase ( $r M t L)$. The chromogenic substrate used was syringaldazine. Under aerobic conditions, $r M t L$ catalyses the oxidation of syringaldazine forming tetrametoxy-azo bis methylene quinone. The developed violet colour was measured kinetically at $530 \mathrm{~nm}$ as an expression of the enzyme activity. $r M t L$ is a very sensitive oxidoreductase, therefore many factors had to be carefully controlled in order to get a robust analytical assay. In order to stabilize rMtL, PEG 6000 was added to the enzyme dilution medium. Furthermore, Triton X-100 was included in the enzyme incubation solution.

The analytical as well as technical conditions have been optimized, resulting in a method with good precision, sensitivity and speed of analysis. The Michaelis-Menten constant, $K_{m}$, was determined to be $22 \mu M$ syringaldazine. LOQ was determined to be $0.010 \mathrm{Uml}^{-1}, \mathrm{LOD}$ to be $0.0002 \mathrm{Uml}^{-1}$. The analytical range of the enzyme dilution curve was from 0.01 to $0.044 \mathrm{Uml}^{-1}$. The repeatability was $1.9 \%$, the reproducibility $3.1 \%$. Testing the robustness of the method showed that the most sensible factors in the $\mathrm{rMtL}$ analysis in decreasing range were: incubation temperature, concentration of Triton X-100, molarity and $p H$ of the incubation buffer, and finally the concentration of syringaldazine.

\section{Introduction}

Laccase, p-diphenol: $\mathrm{O}_{2}$ oxidoreductase (EC 1.10.3.2.) $\mathrm{rMtL}$ is an extracellular oxidoreductase formed during aerobic fermentation of a soft-rot fungus, the thermophilic ascomycete, Myceliophthora thermophila (earlier called Sporotrichum thermophile). At Novo Nordisk, the gene responsible for the formation of $\mathrm{rMtL}$ was expressed in a strain of Aspergillus oryzae using recombinant DNA technique $[1,2]$. The $\mathrm{rMtL}$ protein is an acidic glycoprotein with an $85 \mathrm{kDa}$ molecular mass. The protein is composed of 572 amino acids and is highly glycosylated between 20 and 40\% (mannose, 55\%; galactose, 39\%; and glucosamine, $6 \%$ ). Native MtL has a molecular mass of $80 \mathrm{kDa}$. The difference in molecular mass between $\mathrm{rMtL}$ and native $\mathrm{MtL}$ is primarily caused by a different degree of glycosylation.

The enzyme is $\mathrm{N}$-terminal blocked with $\mathrm{N}$ terminal pyroglutamate residues. $\mathrm{pI}$ is 4.2 [3-5]. rMtL has four copper atoms in the active site and a distinctive threesubdomain structure. The rMtL contains one type 1, T1, site and one type 4, T4, trinuclear copper cluster. The T1 site is in domain 3, whereas the trinuclear cluster is at the border between domains 1 and 3 with ligands from each domain. Furthermore, there are three S-S bindings. Copper in laccase enzymes involves inner-sphere electron transfer in binding activation and reduction of, e.g. dioxygen.

Functionally, rMtL couples the four electron reduction of dioxygen to water with the oxidation of a given substrate. The redox potential $\left(E_{\mathrm{o}}\right)$ for the $\mathrm{rMtL}$ laccase is about $465 \mathrm{mV}$, whereas the laccase from the basidiomycete Polyporus pinsitus has an $E_{\mathrm{o}}$ value of about $775 \mathrm{mV}$. The reason for the very high reduction potentials among fungal laccases remains to be determined [6].

The function of the $\mathrm{T} 1$ site within the enzyme is longrange intramolecular electron transfer, shuttling electrons from the substrate to the trinuclear cluster. The electrons are transferred from the $\mathrm{T} 1$ copper to the trinuclear cluster approximately $13 \AA$ away along the cysteine-histidine pathway. The trinuclear cluster is the site of dioxygen binding and reduction. There are several main functions of laccases. Degrading lignin different enzymes operate synergistically. Laccases may, e.g. remove potentially toxic phenols produced during lignin degradation [7]. Also, laccases appear to be involved in sporulation [8], pigment production [9] and plant pathogenesis, detoxification [10].

\section{Reaction mechanism of laccase}

Molecular oxygen is chemically inert, and a catalyst, e.g. $\mathrm{rMtL}$, is needed in order to reduce dioxygen. In the determination of the activity of $\mathrm{rMtL}$, molecular oxygen is used as a final electron acceptor. Atmospheric dioxygen is directly reduced to oxygen in two molecules of water during liberation of four electrons without hydrogen peroxide being an intermediate step. Laccases catalyse the oxidation of phenolic compounds, and are found in both plants and fungi [11]. The metabolic pathway of syringic and vanillic acids is to a great extent dependent on the $\mathrm{pH}$ of the reaction [12]. The operation mode of a laccase enzyme is, e.g. examined with Rhus species, which in the white sap contain phenols (uristriol, laccal). These phenols are catalysed by laccase, and in the presence of dioxygen oxidized into quinones. Hereby, active radicals are formed, which spontaneously are polymerized, protecting the structure, comparable to the blood clotting system in mammals. 


\section{Theory}

\section{Choice of substrate chromophore}

rMtL has a low level of specificity towards the reductant. Therefore, many compounds have been used as substrates in the activity determination of laccases, e.g. guajacol [13], 2,4 dimetoxyphenol [14], 2,2-azino-bis(3ethyl-benzothiazoline-6-sulphonate) (ABTS), ABTS combined with para-hydroxybenzoic acid/ $\mathrm{NaN}_{3}[15$, 16] and syringaldazine [17-20]. Most of these substrates are insoluble in water. This paper represents the work using syringaldazine $(\mathrm{pKa}=8.8)$ as the substrate chromophore [21].

The oxidation of the diphenolic syringaldazine involves the release of two protons. Compared to that, ABTS is a non-phenolic benzothiazoline compound, thus no use as a substrate chromophore detecting laccase activity. The present laccase is defined here as a p-diphenol: $\mathrm{O}_{2}$ oxidoreductase, meaning that at least two phenolic groups in the para position have to be involved in the reaction. Of the given substrates, only syringaldazine fulfils this criterion. Syringaldazine is moderately water soluble, and the reaction product is well defined [22]

The principle of the present method is as follows: under aerobic conditions, $\mathrm{rMtL}$ laccase catalyses the oxidation of syringaldazine, forming tetrametoxy-bismethylene quinone. The violet colour thus formed is measured kinetically at $530 \mathrm{~nm}$. For the reaction survey, see figure 1 .

\section{Description of the manual LAMU method}

One LAMU unit is the amount of enzyme capable of converting $1 \mu \mathrm{mol}$ of syringaldazine per min under the given reaction conditions.

All the reagents used throughout this work were of analytical grade and prepared with water of MilliQ quality. A stock solution was composed of syringaldazine (0.56 $\mathrm{mM}$ dissolved in $96 \%$ ethanol). Prior to analysis, the syringaldazine was diluted with water to $0.28 \mathrm{mM}$. In the manual method, $4.0 \mathrm{ml}$ of TRIS buffer, $25 \mathrm{mM}$, $\mathrm{pH} 7.5$, was preheated for $10 \mathrm{~min}$ at $30^{\circ} \mathrm{C}$. Afterwards, $100 \mu \mathrm{l}$ of enzyme dilution was added under mixing. Finally, $300 \mu \mathrm{l}$ of syringaldazine $(0.28 \mathrm{mM})$ was added
2

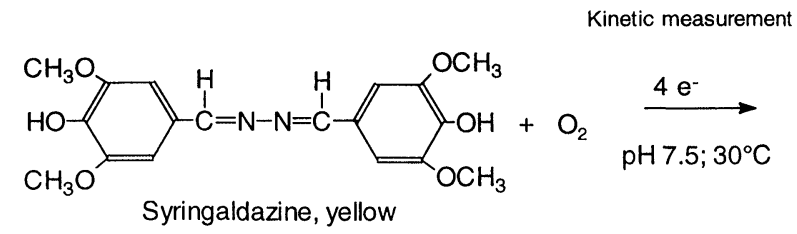

\section{Tetrametoxy azobismethylene quinone, violet}

Figure 1. Overview of the conditions for the $r M t L$-syringaldazine reaction. under mixing. The incubation temperature was $30^{\circ} \mathrm{C}$ during the kinetic measurement in a cuvette $(530 \mathrm{~nm})$. A lag phase occurred in the reaction. Therefore, the difference in absorbance values, $A_{90 \mathrm{~s}}-A_{60 \mathrm{~s}}$, was correlated to the enzyme activity. Regarding the calculation, a $\mu \mathrm{mol}$ extinction coefficient at 0.065 of the formed tetraoxybismethylene quinone was used [17]. Note that the order in which the different reagents were mixed in the analysis was a critical parameter.

\section{Choice of incubation buffer}

Regarding the stability of $\mathrm{rMtL}$, different buffers were tested using routine conditions. The buffers were $(0.1 \mathrm{M})$ : TRIS, MOPS, HEPES, TAPS and PIPES. The best choice was TRIS buffer with a satisfying buffer capacity at $\mathrm{pH} 7-9$.

\section{pH activity}

Using the routine analytical conditions, the optimum of the $\mathrm{pH}$ activity curve for a highly purified laccase sample was determined. The $\mathrm{pH}$ value was dependent on the type of buffer used as well as on the buffer molarity. If, e.g. a combined buffer of sodium acetate $(50 \mathrm{mM})$ and sodium phosphate $(50 \mathrm{mM})$ was used, the $\mathrm{pH}$ maximum was 6.5. Using a combined buffer composed of sodium acetate $(25 \mathrm{mM})$ and TRIS $(25 \mathrm{mM})$, the maximum was $\mathrm{pH}$ 7.0. Analysing with a pure TRIS buffer, $25 \mathrm{mM}$, the $\mathrm{pH}$ optimum changed to $\mathrm{pH}$ 7.5. This $\mathrm{pH}$ value was chosen as a routine condition (see figure 2 ).

\section{Temperature activity}

Routine analytical conditions were used. The results are shown in figure 3 . The temperature optimum was found to be $70^{\circ} \mathrm{C}(t=90 \mathrm{~s})$. As the sensitivity of the syringaldazine reaction was at a satisfying level, $30^{\circ} \mathrm{C}$ was preferred as the routine temperature during the reaction.

\section{Enzyme dilution medium}

In highly diluted solutions, oxidoreductase enzymes in general are unstable, which from an analytical point of view is a critical aspect. An example is peroxidase, where

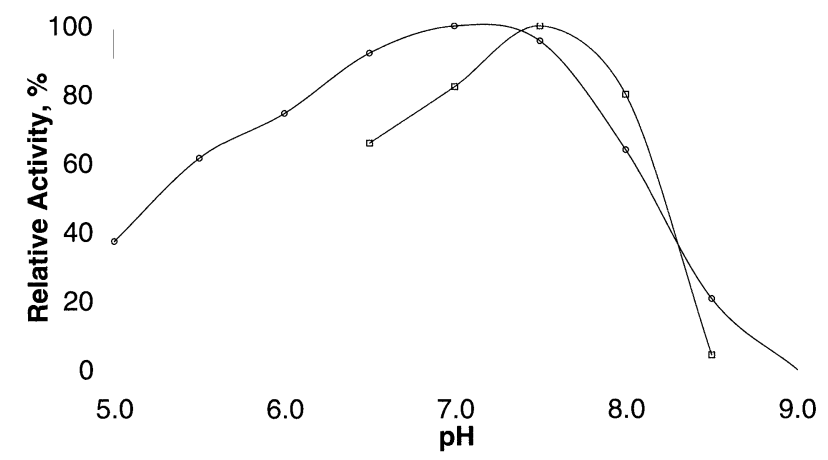

Figure 2. pH activity curve with a combined buffer composed of sodium acetate $(25 \mathrm{mM})$ and sodium phosphate $(25 \mathrm{mM})$ [O]. $p H$ range: 5.0-9.0, $p H$ activity curve with a pure Tris buffer (25 $\mathrm{mM}) .[\square]$. pH range: $6.5-8.5$. 


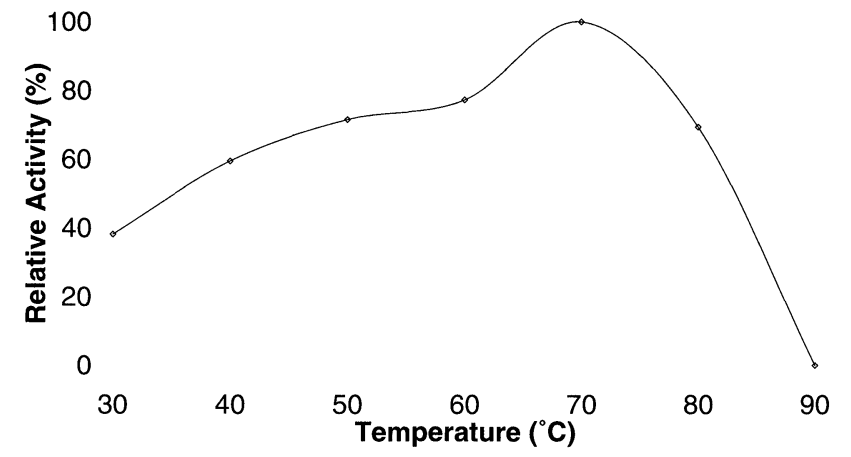

Figure 3. Temperature activity from $30^{\circ} \mathrm{C}$ to $90^{\circ} \mathrm{C}$.

an addition of Triton X-405 was essential for the stabilization of the enzyme protein [23]. The same consideration might be transferred to rMtL. Therefore, in order to get a stabile and robust analytical method determining the activity of $\mathrm{rMtL}$, stabilization of the laccase enzyme protein was essential prior to the analysis. Different compounds were tested as enzyme dilution medium. PEG 6000, Triton X-100 and bovine serum albumin, respectively, were each prepared in a solution of $1 \mathrm{gl}^{-1}$. The best result was obtained with the PEG 6000 .

\section{Choice of the concentration of PEG 6000}

Different concentrations of PEG $6000\left(1-50 \mathrm{gl}^{-1}\right)$ were dissolved in water and tested as the enzyme dilution medium. Routine analytical conditions were used. Addition of $\mathrm{PEG}, 50 \mathrm{gl}^{-1}$, resulted in the best stability of rMtL. Higher concentrations of PEG were also examined, but no further improvement in the stability of the $\mathrm{rMtL}$ was obtained. Therefore, PEG 6000, $50 \mathrm{gl}^{-1}$, was chosen as the routine condition.

\section{Addition of different salts}

The following salts were successively added to the enzyme dilution medium ( $50 \mathrm{~g}$ of PEG $6000 \mathrm{l}^{-1}$ ) in order to examine a possible interference on the rMtL assay. Routine analytical conditions were used. Potassium chloride (KCl) 1-200 $\mathrm{gl}^{-1}$, cupric sulphate $\left(\mathrm{CuSO}_{4}\right)$ 10-100 $\mathrm{mgl}^{-1}$, magnesium sulphate $\left(\mathrm{MgSO}_{4}\right) 1 \mathrm{gl}^{-1}$ and magnesium chloride $\left(\mathrm{MgCl}_{2}\right) 1 \mathrm{gl}^{-1}$ were added, respectively. With the given concentrations, only the addition of $\mathrm{KCl}$ caused a decrease in activity. The following example showed that the chloride ion was responsible for this decreasing effect.

\section{The effect of sodium chloride}

In order to make a further examination of the chloride effect on the $\mathrm{rMtL}$ assay, sodium chloride ( $\mathrm{NaCl}$ ) was introduced to the enzyme dilution medium (PEG $50 \mathrm{gl}^{-1}$ ) applying different concentrations hereof. The results are shown in table 1 . The chloride ion had a very negative influence on the enzyme activity, and a $5 \%$ decrease in response was seen by adding only $1 \mathrm{gl}^{-1}$. In order to avoid the chloride ion, the TRIS buffer used was adjusted to $\mathrm{pH} 7.5$ with maleic acid.
Table 1. Addition of sodium chloride to the enzyme dilution medium.

\begin{tabular}{lc}
\hline & Relative Activity \% \\
\hline Reference & 100 \\
$\mathrm{NaCl}, 1 \mathrm{gl}^{-1}$ & 95 \\
$\mathrm{NaCl}, 10 \mathrm{gl}^{-1}$ & 89 \\
$\mathrm{NaCl}, 100 \mathrm{gl}^{-1}$ & 61 \\
$\mathrm{NaCl}, 200 \mathrm{gl}^{-1}$ & 59 \\
\hline
\end{tabular}

Table 2. Addition of sulphate or phosphate ions to the enzyme dilution medium

\begin{tabular}{lc}
\hline & Relative Activity \% \\
\hline Reference & 100 \\
$\mathrm{Na}_{2} \mathrm{SO}_{4}, 0.5 \mathrm{gl}^{-1}$ & 99 \\
$\mathrm{Na}_{2} \mathrm{SO}_{4}, 1 \mathrm{gl}^{-1}$ & 101 \\
$\mathrm{Na}_{2} \mathrm{SO}_{4}, 10 \mathrm{gl}^{-1}$ & 98 \\
$\mathrm{Na}_{2} \mathrm{SO}_{4}, 100 \mathrm{gl}^{-1}$ & 90 \\
$\mathrm{Na}_{2} \mathrm{SO}_{4}, 200 \mathrm{gl}^{-1}$ & 80 \\
$\mathrm{Na}_{2} \mathrm{HPO}_{4}, 0.5 \mathrm{gl}^{-1}$ & 100 \\
$\mathrm{Na}_{2} \mathrm{HPO}_{4}, 1 \mathrm{gl}^{-1}$ & 95 \\
$\mathrm{Na}_{2} \mathrm{HPO}_{4}, 10 \mathrm{gl}^{-1}$ & 94 \\
$\mathrm{Na}_{2} \mathrm{HPO}_{4}, 50 \mathrm{gl}^{-1}$ & 83 \\
$\mathrm{Na}_{2} \mathrm{HPO}_{4}, 100 \mathrm{gl}^{-1}$ & 76 \\
\hline
\end{tabular}

\section{The effect of sulphate or phosphate ions}

Different concentrations of sulphate or phosphate ions were added to the dilution medium (PEG $50 \mathrm{gl}^{-1}$ ) testing the influence on the stability of the rMtL. The obtained results are shown in table 2. Both sulphate and phosphate ions seemed to have a negative effect on the rMtL, and should be avoided in concentrations higher than $10 \mathrm{gl}^{-1}$.

\section{Addition of Triton $X-100$}

Addition of Triton X-100 to the enzyme dilution medium and/or to the incubation buffer was also tried. The best result was achieved by adding $10 \mathrm{~g}$ of Triton X-100 $\mathrm{l}^{-1}$ to the enzyme dilution medium (in addition to the routinely used $50 \mathrm{~g}$ of PEG $6000 \mathrm{l}^{-1}$ ). Addition of Triton $\mathrm{X}-100$ to the incubation buffer did not improve the stabilization during kinetic measurement.

\section{Conclusion: Manual method}

A method determining the activity of $\mathrm{rMtL}$ was developed with the following conditions:

Incubation buffer $\quad 4.0 \mathrm{ml}$ of TRIS buffer, $\mathrm{pH} 7.5$, $25 \mathrm{mM}$

Enzyme dilution medium $50 \mathrm{~g}$ of PEG $6000 \mathrm{l}^{-1}$ and $10 \mathrm{~g}$ of Triton X-100 $1^{-1}$ dissolved in water.

Sample volume $\quad 100 \mu \mathrm{l}$ (enzyme activity range: $0.07-0.28 \mathrm{LAMUml}^{-1}$ )

Substrate chromophore Syringaldazine $0.28 \mathrm{mM}$ (dissolved in $48 \%$ ethanol) 
Syringaldazine- $\mathrm{R}$ volume $300 \mu \mathrm{l}$

Incubation temperature $30^{\circ} \mathrm{C}$

Wavelength

$530 \mathrm{~nm}$

Kinetic measuring from $60-90 \mathrm{~s}$

Calculation

$t_{90 \mathrm{~s}}-t_{60 \mathrm{~s}}$ (linear part of the

kinetic curve)

\section{The automated $\langle$ COBAS $\rangle$ FARA method}

\section{Experimental}

After development of the manual method determining the activity of $\mathrm{rMtL}$, an automated Cobas Fara method was evaluated using the results obtained in the development of the manual method.

\section{Apparatus}

An automated centrifugal analyser, a Cobas Fara from Hofmann-La Roche, Basel, Switzerland, was used. This instrument was well suited for kinetic measurements, having a great capacity for analyses.

\section{Reagents}

All the reagents used were of analytical grade. The water used was of MilliQ water quality. TRIS buffer stock solution, 1 M, 121.1 g of TRIS (hydroxymethyl) aminomethane (Sigma, USA) was dissolved in 11 of water.

Maleic acid (Merck 800380, Germany) was prepared by dissolving $23.2 \mathrm{~g}$ in $200 \mathrm{ml}$ of water. Triton X-100, stock solution $10 \%$, prepared by dissolving $25.0 \mathrm{~g}$ in $250 \mathrm{ml}$ of water. TRIS buffer, $25 \mathrm{mM}, \mathrm{pH} 7.5$. Application solution, $12.5 \mathrm{ml}$ of TRIS buffer stock solution, $5.0 \mathrm{ml}$ of maleic acid stock solution, $2.5 \mathrm{ml}$ of Triton X-100 stock solution and water up to $500 \mathrm{ml}$.

Enzyme dilution medium, $50.0 \mathrm{~g}$ of PEG 6000 (Merck, Germany) was dissolved in 11 of water.

Syringaldazine stock solution, $0.56 \mathrm{mM}, 10.0 \mathrm{mg}$ of syringaldazine (S-7896, Sigma, USA) was dissolved in $96 \%$ ethanol (Danisco, Denmark). Stability was one month at $-18^{\circ} \mathrm{C}$. Syringaldazine: solution for application, $0.22 \mathrm{mM}, 4.0 \mathrm{ml}$ of the syringaldazine stock solution and made up to $10 \mathrm{ml}$ with water.

Check for the syringaldazine reagent: $2.0 \mathrm{ml}$ of $0.22 \mathrm{mM}$ syringaldazine reagent, $4.0 \mathrm{ml}$ of $96 \%$ ethanol and made up to $10.0 \mathrm{ml}$ with water. The absorbance of this solution should be about $1.8 \mathrm{read}$ at $360 \mathrm{~nm}$ (against 6\% ethanol).

\section{Samples}

A highly refined $\mathrm{rMtL}$ preparation was used throughout this work. The preparation was refined at Novo Nordisk (2019 LAMUg $^{-1}$ ). Fermentation sample: the process sample from Novo Nordisk was used.

\section{Procedure}

The samples were diluted to approx. $0.025 \mathrm{LAMUml}^{-1}$. The dilution medium was $50 \mathrm{~g}$ of PEG 6000 dissolved in
11 of water. Due to an enzyme activation phase, the diluted samples had to stand for at least $15 \mathrm{~min}$ before analysing on the Cobas Fara analyser. The working area ranged from 0.010 to $0.044 \mathrm{LAMUml}^{-1}$.

Reagents and samples were placed in racks before being dispensed by the pipette tool of the Cobas Fara, respectively. The sample volume was $25 \mu \mathrm{l}$, water $20 \mu \mathrm{l}$ and buffer volume $325 \mu \mathrm{l}$. The rotor with the cuvettes started to accelerate, thus mixing the volumes. Finally, $30 \mu \mathrm{l}$ of syringaldazine was pipetted into the small compartment of the rotor. When the incubation temperature had reached its level, the centrifugation started, and the absorbance readings took place. A total of 25 absorbance values was read from each curette with an interval of $5 \mathrm{~s}$. Rectilinear kinetic measurements obtained between the 12 th and 24 th reading were used for the calculation, and the absorbance per minute was calculated for each sample.

\section{Calculation}

Unit definition: as already defined, 1 LAMU unit is the amount of enzyme capable of converting $1 \mu \mathrm{mol}$ syringaldazine per min under the given reaction conditions.

$$
\begin{aligned}
& (A \times \mathrm{Vol} \times D) \times W^{-1}=\mathrm{LAMUg}^{-1} \\
& A=F \times \mathrm{ABS} \times \min ^{-1}\left(\mathrm{LAMU} \mathrm{g}^{-1}\right)
\end{aligned}
$$

where: $\mathrm{Vol}=$ sample dilution volume $(\mathrm{ml}) ; D=$ further dilution of the sample $\left(\mathrm{ml} \mathrm{ml}^{-1}\right) ; W=$ weight of the sample in work $(\mathrm{g})$.

$$
F=V \times 10^{-3} \times(v \times E \times b)^{-1}
$$

where: $V=$ total volume in the reaction solution $(\mathrm{ml})$; $v=$ sample volume in the reaction solution (ml); $E=\mu$ molar extinction coefficient at $530 \mathrm{~nm}(0.065$ per $1 \mathrm{~cm}$ light path); $b=$ light path. The total volume in the reaction is $400 \mu \mathrm{l}$. That volume corresponds to a light path in the cuvette at $1.6 \mathrm{~cm} ; 10^{-3}$ is $\mu \mathrm{mol} \mathrm{l}^{-1}$ converted to $\mu \mathrm{mol} \mathrm{ml} \mathrm{m}^{-1}$.

\section{Addition of Triton X-100 to the incubation buffer}

In order to avoid adhesion problems in the Cobas Fara system, Triton X-100 was added to the incubation buffer. Two concentrations of Triton X-100 (0.5 and $\left.10 \mathrm{~g} \mathrm{l}^{-1}\right)$ were added to the incubation buffer (TRIS, $25 \mathrm{mM}$, $\mathrm{pH} 7.5$ ) using $50 \mathrm{~g}$ of PEG $6000 \mathrm{1}^{-1}$ dissolved in water as the enzyme dilution medium. The best result was obtained with $0.5 \mathrm{~g}$ of Triton $\mathrm{X}-100 \mathrm{l}^{-1}$. Addition of higher concentrations of Triton X-100 was really a critical parameter, e.g. using $10 \mathrm{gl}^{-1}$ hereof gave a residual laccase activity of less than $50 \%$.

\section{Stabilization of $r M t L$ in the enzyme dilution medium}

Various concentrations of PEG 6000 were used as enzyme dilution media: $1,10,25$ and $50 \mathrm{gl}^{-1}$. The best enzyme stability and linearity of the enzyme standard curve were found using $50 \mathrm{~g}$ of PEG $6000 \mathrm{1}^{-1}$ without any addition of Triton X-100 to the enzyme dilution medium. 


\section{Activation of $r M t L$}

Using the routine analytical conditions, the activation of the $\mathrm{rMtL}$ in the final sample dilution was examined. A highly refined sample as well as a fermentation sample were analysed immediately after the dilution ( $5 \mathrm{~min}$ ), and reanalysed after 14, 25, 45 and $60 \mathrm{~min}$, respectively. The activity increased slightly, about $2 \%$, within the first $10 \mathrm{~min}$. Consequently, the diluted $\mathrm{rMtL}$ solutions had to be activated for at least $15 \mathrm{~min}$ before analysis.

\section{Determination of the Michaelis-Menten constant $\left(\mathrm{K}_{m}\right)$}

Regarding the given reaction to be either a reaction of 0 order or pseudo lst order, the $K_{\mathrm{m}}$ was determined. The sample was diluted in two levels and analysed at two different concentrations of the substrate $(0.28$ and $0.14 \mathrm{mM})$. Using Hanes plot [24], the average $K_{\mathrm{m}}$ value was found to be $22 \mu \mathrm{M}$, which shows a high degree of affinity between $\mathrm{rMtL}$ and syringaldazine. Therefore, the actual substrate concentration was found to be at a satisfying level 10 times higher than the $K_{\mathrm{m}}$ value.

\section{Enzyme working range}

The working range was determined to be from 0.010 to 0.044 LAMUml $^{-1}$.

\section{Precision, $L O D$ and $L O Q$}

The precision of the present method [25] was examined within a day expressed by repeatability and between days by the reproducibility. The repeatability for a given sample analysing five levels each with six separate dilutions was $1.9 \%$. The reproducibility for a sample also analysed at four levels with two separate dilutions over six days was found to $3.1 \%$. The limit of detection (LOD) and limit of quantitation (LOQ) were calculated to be $0.0002 \mathrm{LAMUml}^{-1}$ and $0.010 \mathrm{LAMUml}^{-1}$, respectively.

\section{Robustness of the method}

Testing the robustness of the method [25] showed that many parameters were important re stabilization of the analytical conditions. The most critical ones were, in decreasing order: incubation temperature, concentration of Triton X-100, molarity and $\mathrm{pH}$ of the incubation buffer, and the concentration of syringaldazine. The results were validated according to Youden's test [26].

\section{Conclusion, Cobas Fara method}

A Cobas Fara method determining the activity of $\mathrm{rMtL}$ was developed. The following analytical conditions were chosen:

\section{Incubation buffer}

Enzyme diluent TRIS buffer $25 \mathrm{mM}, \mathrm{pH} 7.5$, $0.5 \mathrm{~g}$ of Triton X-100 $1^{-1}$. $50 \mathrm{~g}$ of $\mathrm{PEG}^{-1}$

Substrate chromophore Syringaldazine $0.22 \mathrm{mM}$ Incubation temperature $30^{\circ} \mathrm{C}$
Wavelength
$530 \mathrm{~nm}$
Kinetic measurement from 60 to $120 \mathrm{~s}$

From an analytical point of view, $\mathrm{rMtL}$ was a very delicate oxidoreductase, where many factors had to be under control in order to get a robust analytical assay.

Stability of the diluted sample: $>8 \mathrm{~h}$ at $22^{\circ} \mathrm{C}$.

Stability of the syringaldazine application reagent: $2 \mathrm{~h}$ at $22^{\circ} \mathrm{C}$.

\section{Summary}

Determining the LAMU activity, an automated and fast routine method using a Cobas Fara analyser was developed. The method is sensitive with good precision. The type of samples may either be fermentation samples or highly purified samples. Analysing 30 samples, the analytical time from sample uptake to appearance of recorder response is about $15 \mathrm{~min}$.

\section{References}

1. Christensen, T., Wøldike, H., Bofi, E., Mortensen, S. B., HjortshøJ, K., Thim, L. and Hansen, M. T., 1988, Biotechnology, 6, 1419.

2. Christensen, T., 1994, Application: Aspergillus oryzae as host for production of industrial enzymes. FEMS Symp., 69, 251.

3. Yaver, D. S., Xu, F. and Schneider, P., 1996, Appl. Environ. Microb., 62, 834.

4. Mondorf, K., 1994, NOVO Nordisk Report.

5. Berka, R. M., Schneider, P., Golightey, E. J. and Brown, S. H., 1997, Appl. Environ. Microb., 6, 3151.

6. Solomon, E. I., Sundaram, U. M. and Machokin, T. E., 1996, Chem. Rev., 2563.

7. Youn, H.-D., НAн,Y. C. and KAng, S.-O., 1995, FEMS Microbiology Letters, 132, 183.

8. Leathan, G. and STromman, M. A., 1981, 7. Gen. Microbiol., 125, 147.

9. Tanaka, C., Tajima, S. and Furusava, M., 1992, Mycol. Res., 96, 959

10. Marbach, I., Harel, E. and Mayer, A. M., 1985, Phytochemistry, 24, 2559.

11. Mayer, A. M., 1987, Phytochemistry, 26, 11.

12. Leonowicz, A., Edehill, R. U. and Bollag, J.-M., 1984, Arch. Microbiol., 137, 89.

13. Zuohri, N., Romette, J. L. and Thomas, D., 1987, Appl. Biochem. Biotechnol., 15, 213.

14. Shuttleworth, K. L. and Bollag, J.-M., 1986, Enzyme Microb. Technol., 8, 171.

15. Shin, T., Muran, S. and Matsumura, E., 1987, Anal. Biochem., 166 380.

16. Mutao, S., 1985, 7. Pharm. Society of Japan, 105, 86.

17. Bauer, R. and Rupe, C. O., 1971, Anal. Chem., 43, 421.

18. Petroski, R.J., Peczynska-Czoch, W. and Rosazza, J. P., 1980, Appl. Environ. Microb., 40, 1003.

19. Leonowics, A. and Grzyknowicsz, K., 1981, Enzyme Microb. Technol., 3, 55.

20. Ander, P. and Eriksson, K.-L., 1987, Biotech. Appl. Biochem., 9, 160.

21. Hapiot, P. and Pinson, J., 1993, 7. Electroanal. Chem., 353, 225.

22. Wahleithner, J .A., Xu, F., Brown, K. M. and Brown, S. H., 1996, Curr. Genet., 29, 3.

23. Holm, K. A., 1995, Analyst, 120, 2101.

24. HANes, G. S., 1932, Biochem. J., 26, 1406.

25. Holm, K. A., 1996, Novo Nordisk validation report re LAMU assay.

26. Youden, W. J. and Steiner, E. H., 1975, Statistical manual of the association of official analytical chemist. $A O A C$. 


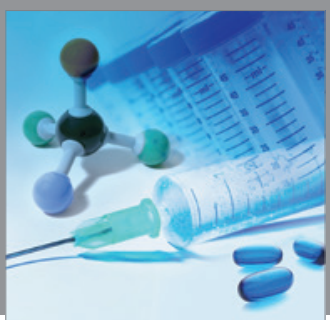

International Journal of

Medicinal Chemistry

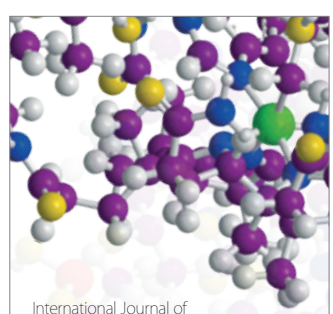

Carbohydrate Chemistry

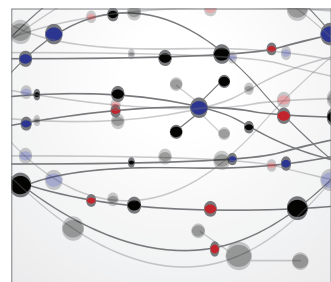

The Scientific World Journal
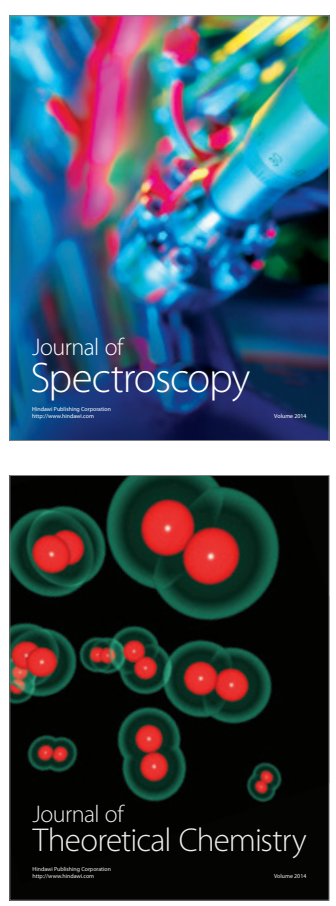
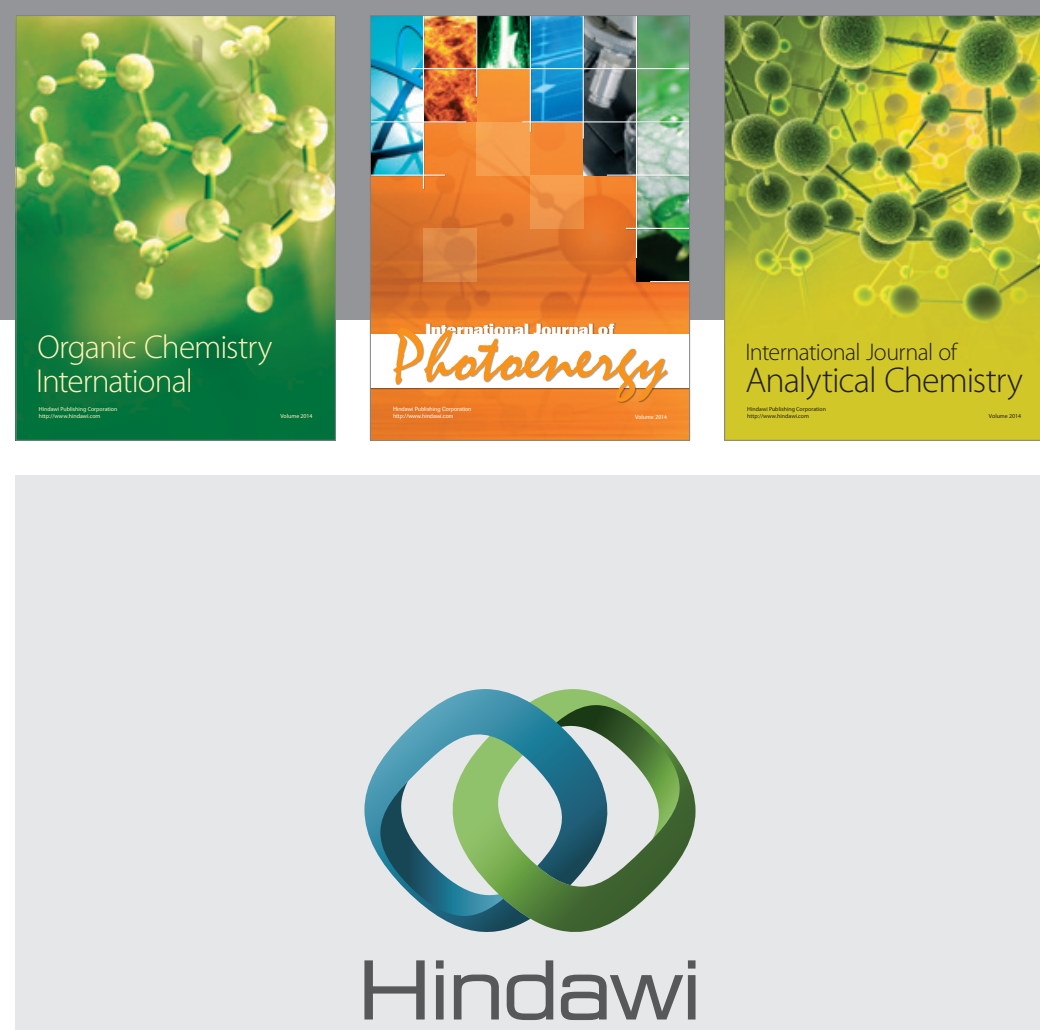

Submit your manuscripts at

http://www.hindawi.com
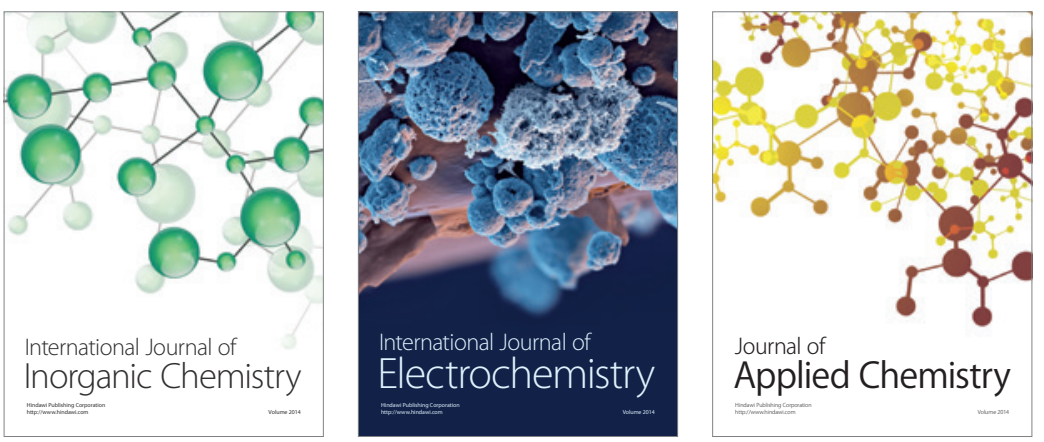

Journal of

Applied Chemistry
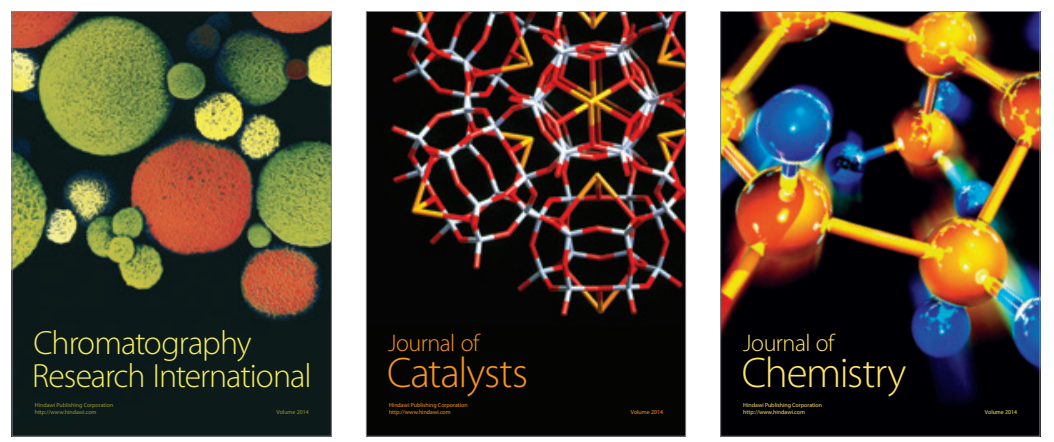
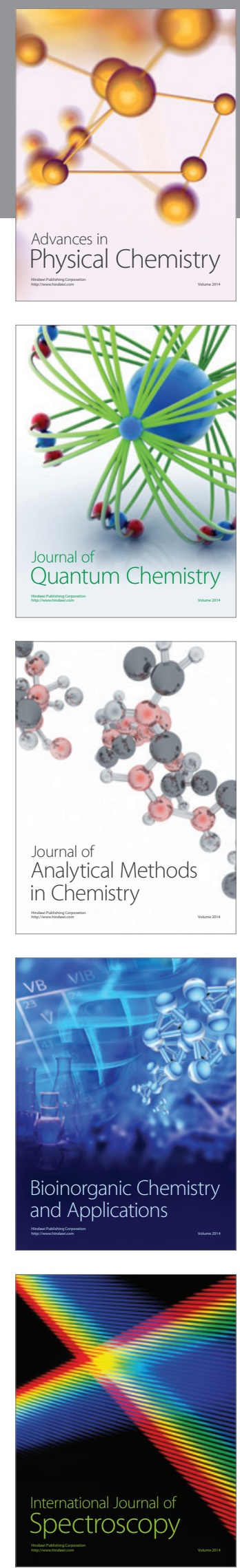